\title{
A INSERÇÃO DE LÍNGUAS ESTRANGEIRAS NOS ANOS INICIAIS DE ESCOLARIZAÇÃO E A BASE NACIONAL COMUM CURRICULAR: SILENCIAMENTO INOCENTE OU OMISSÃO PROPOSITAL ${ }^{1}$
}

\author{
The Insertion of Foreign Languages in the Early Years of Schooling and the \\ Brazilian National Curriculum: Naïve Silencing or Purposeful Omission?
}

\author{
Juliana Reichert Assunção TONELLI \\ Universidade Estadual de Londrina \\ jtonelli@uel.br \\ https://orcid.org/0000-0001-5102-5847
}

Paula Aparecida AVILA Colégio Estadual Odete Borges Botelho prof.paulaavila@hotmail.com https://orcid.org/0000-0001-9310-5810

\begin{abstract}
RESUMO: A problemática que envolve a inserção de línguas estrangeiras (LE) nos anos iniciais de escolarização (educação infantil ao $5^{\circ}$ ano do primeiro ciclo do ensino fundamental) tem sido tema de estudos desenvolvidos no campo da linguística aplicada no Brasil. O objetivo deste artigo é 1) apresentar uma reflexão acerca da implementação de aulas de LE na rede pública de ensino em nosso país e o que tais ações podem indicar sobre políticas linguísticas nesta etapa da escolarização, e 2) problematizar se a ausência de documentos oficiais indica silenciamento ou omissão por parte do Estado. Os dados analisados constam de um panorama de teses e dissertações identificadas as quais tratam, direta ou indiretamente, dos desdobramentos inerentes a iniciativas locais para a oferta da língua inglesa na infância (LIC) e os reflexos nas políticas. Os resultados indicam que as políticas em LIC existem na prática, mas são raros os casos em que se concretizam no texto.
\end{abstract}

PALAVRAS-CHAVE: Ensino fundamental; Línguas estrangeiras; Políticas; Base nacional comum curricular.

ABSTRACT: The issue concerning the insertion of foreign languages (FL) in the early years of schooling (Kindergarten to the 5th year of the

\footnotetext{
${ }^{1}$ Recorte da dissertação de mestrado da segunda autora, defendida no Programa de Pós-Graduação em Estudos da Linguagem na Universidade Estadual de Londrina (UEL), sob orientação da primeira. Considerando as questões éticas de coautoria, este artigo foi escrito pelas autoras a partir das reflexões durante e após o processo de orientação. A investigação, inserida no Grupo de Pesquisa FELICE/CNPq, foi aprovada pelo Comitê de Ética envolvendo Seres Humanos da UEL (CAE 81070117.7.0000.5231).
} 
first Cycle of Elementary School) has been the subject of studies developed in the field of applied linguistics in Brazil. The purpose of this article is to present a reflection on the implementation of FL classes in the public-school system in our country and what these actions may indicate about language policies at this stage of schooling. We also seek to question whether the absence of official educational guidelines indicates silencing or omission from the State. The analyzed data consist of a panorama of identified theses and dissertations which deal, directly or indirectly, with the developments inherent to local initiatives for the provision of the English language in childhood (ELC) and the reflexes on policies. The results indicate that ELC policies exist in practice, but there are rare cases in which they are materialized in the text.

KEYWORDS: Elementary School; Foreign Languages; Policies; Brazilian National Curriculum.

\section{INTRODUÇÃO}

Nos últimos anos, temos observado a significativa expansão do ensino de línguas estrangeiras para crianças $(\text { LEC })^{2}$ - especialmente a língua inglesa (LI) - na educação infantil (EI) e no ensino fundamental I (EFI) ${ }^{3}$.

Embora a LI venha ganhando cada vez mais espaço nas escolas privadas e públicas de EI e de EFI do Brasil, há, ainda, a carência de documentos norteadores para seu ensino (GIMENEZ, 2013; CHAGURI; TONELLI, 2013) visto que a obrigatoriedade da oferta de uma língua estrangeira (LE) acontece, por $\mathrm{lei}^{4}$, somente a partir do sexto ano e é facultativa nas etapas anteriores de escolaridade.

Neste artigo apresentamos uma breve reflexão acerca da implementação de aulas de LEC na rede pública de ensino em nosso país e o que tal ação pode indicar sobre políticas linguísticas. Problematizamos, ainda, se a ausência de documentos oficiais indica silenciamento ou omissão por parte do Estado. Os dados analisados constam de sete pesquisas que tratam, direta ou indiretamente, dos desdobramentos inerentes a iniciativas locais para a oferta de LEC, em especial de LI.

\footnotetext{
${ }^{2}$ Conforme o Estatuto da Criança e do Adolescente (lei 8.609 de 13 de julho de 1990), é considerada criança a pessoa de até 12 anos incompletos.

${ }^{3}$ Do $1^{\circ}$ ao $5^{\circ}$ ano.

${ }^{4}$ De acordo com a resolução CNE/CEB n 7 de 14 de dezembro de 2010 que fixa as Diretrizes Curriculares Nacionais (DCNs) para o ensino de nove anos (BRASIL, 2010).
} 
O texto está organizado em cinco partes. Na primeira, recuperamos teorias sobre políticas linguísticas para, em seguida, situá-las no ensino de LI nos anos iniciais de escolarização no Brasil. Na sequência, referimo-nos ao status da língua inglesa no mundo, aos documentos oficiais e às políticas linguísticas para o ensino de LEC em nosso país visto que estas, ainda que oficiais, continuam, a nosso ver, oficiosas. Na terceira parte, apresentamos um panorama de trabalhos brasileiros que tratam, direta ou indiretamente, dos desdobramentos inerentes às iniciativas locais de oferta da LI na infância. Posteriormente, trazemos possíveis leituras sobre os resultados e/ou perspectivas apresentados pelas autoras das pesquisas analisadas. A quinta e última parte é dedicada às considerações a que chegamos.

\section{O QUE SÃO POLÍTICAS LINGUÍSTICAS?}

Para atingir o objetivo a que nos propusemos - apresentar uma reflexão acerca da implementação de aulas de LEC na rede pública de ensino no Brasil e seus possíveis desdobramentos no campo das políticas linguísticas em nosso país - propomos uma breve definição do termo política linguística perpassando, também, por uma compreensão dos termos política, política pública e política educacional.

Conforme Rajagopalan (2013), a política, em seu sentido geral, pode ser caracterizada como "a arte de conduzir a governança ou a administração de assuntos públicos de um estado" (RAJAGOPALAN, 2013, p. 21). Segundo Secchi (2013), há dificuldades de países de língua latina em diferenciar alguns termos das ciências políticas, como é o caso da própria palavra política, uma vez que esta, na língua portuguesa, por exemplo, possui dois significados diferentes. O mesmo ocorre com a LI, visto que há duas definições distintas para o vocábulo política: politic(s) e policy (SECCHI, 2013; CORREA, 2013).

Correa (2013, p. 21), por sua vez, afirma que as políticas, enquanto policy, referem-se a "uma série de princípios e/ou ações tomadas por um governo, partido, negócio ou indivíduo”. Já o termo política $(\operatorname{politic}(s))$ é definido pelo autor como referente a "atividades ligadas à governança de um país ou outro território, e, em especial, aos embates e conflitos, individuais ou partidários, com o objetivo de se alcançar o poder" (CORREA, 2013, p. 20-21). 
Secchi (2013), por sua vez, aponta que a política, no sentido de politic é aquela referente às atividades humanas, as quais estão associadas à obtenção e manutenção de recursos necessários para exercer poder sobre o homem. Esse sentido da palavra política, segundo o autor, talvez seja o mais comum entre os falantes da língua portuguesa, sendo cotidianamente aplicado no sentido de atividade política, diferentemente da política enquanto policy, que está relacionada a orientações para a decisão e a ação.

De acordo com Ball (1994), política é um conjunto de tecnologias e práticas realizadas em ambientes locais; ela é texto (palavras) e, ao mesmo tempo é ação, sendo representada de maneiras variadas por diferentes atores e interesses. Segundo Ball e Mainardes (2011), as políticas estão sempre em fluxo, não são estáticas e são entendidas como respostas a problemas oriundos da prática; além disso, não são fixas e imutáveis e podem estar sujeitas a interpretações e traduções diferentes. Neste cerne, trazemos o que Bowe, Ball e Gold (1992) definem como Abordagem do Ciclo de Políticas (ACP), sendo ela relacionada a diversos tipos de contextos, os quais destacamos neste artigo: o contexto de influência, o de produção de textos e o contexto da prática.

$\mathrm{O}$ contexto de influência diz respeito à construção e à legitimidade dos discursos políticos que darão sustentação às políticas públicas. É nele que as políticas normalmente se iniciam e grupos de interesse - partidos políticos, esferas de governo, grupos privados, dentre outros - disputam para influenciar a definição das finalidades sociais (MAINARDES, 2006). Nesse sentido, esse é um contexto relacionado aos movimentos de políticas globais.

Bowe et al. (1992) consideram que os profissionais da educação influenciam os processos de criação e de execução das políticas, pois a ACP "oferece maior ênfase em processos micropolíticos e na agência de diferentes atores (praticantes) de uma política educacional ou social" (CORREA, 2013, p. 26). Outro fator que influencia são as questões globais e internacionais no processo de formulação de políticas nacionais, como a globalização, pois trazem interferências nos discursos e nas práticas dos envolvidos (MAINARDES, 2006).

$\mathrm{O}$ contexto de produção de textos diz respeito aos textos políticos que são concretizados em forma de documentos oficiais e não oficiais, como, por exemplo, "textos legais oficiais e textos políticos, comentários formais ou informais sobre os textos oficiais, 
pronunciamentos oficiais, vídeos etc.” (MAINARDES, 2006, p. 52), textos da mídia, campanhas, dentre outros (CORREA, 2013).

De acordo com Bowe et al. (1992), no contexto da prática as ações serão efetuadas de acordo com a interpretação da política pelos atores envolvidos, podendo ser recriada e ter consequências diferentes das esperadas na política original (MAINARDES, 2006). Esses atores, ou agentes, são os professores e todos os profissionais que vivenciam o dia a dia da escola. É nesse contexto que a política produz efeitos, os quais podem ter consequências diferentes daquelas intencionadas na política original, visto que depende da interpretação dos atores envolvidos. Para Gimenez (2013, p. 201), o contexto da prática é um espaço onde são executadas as ações específicas em (des)consideração aos textos políticos que foram propostos no contexto de produção de textos, pois "esse contexto é de recriação e não apenas de implementação, embora essa recriação seja limitada pelas possibilidades dadas pelos discursos legitimados nos textos".

Segundo Ball (1994), o Estado ${ }^{5}$ é um dos principais atores da política; todavia, para Secchi (2013), ele não é o único protagonista, posto que há outros atores importantes envolvidos nesses processos, os quais podem exercer influência direta ou indireta como, por exemplo, a dinâmica do mercado, as demandas da sociedade civil, as relações internacionais, dentre outros.

Partindo dos conceitos do termo política, adentramos nas definições de política pública e política educacional. Para Secchi (2013), a política pública está vinculada ao termo em inglês policy, portanto, public policy. De acordo com o autor, a política pública está pautada em dois elementos essenciais: a intencionalidade pública e a resposta a um problema público.

Oliveira (2010, p. 98), por sua vez, destaca que esta é "tudo aquilo que um governo faz ou deixa de fazer, bem como os impactos de sua ação ou omissão" e salienta que se o governo não toma uma atitude sobre algo emergente também é caracterizado como uma política pública, visto que envolveu uma decisão. Nesse sentido, compreendemos que a forma como vem ocorrendo a inserção de LEC nas escolas públicas brasileiras, isto é, sem a formação de professores para atuarem com essa faixa etária, carência de documentos

\footnotetext{
${ }^{5}$ Entendemos Estado como uma "nação politicamente organizada por leis próprias; um conjunto das estruturas institucionais que asseguram a ordem e o controle de uma nação". Disponível em: <https://michaelis.uol.com.br/>. Acesso em: 19 abr. 2020.
} 
norteadores, dentre outros aspectos, são alguns dos impactos (negativos) dessa omissão por parte do governo.

Recuperamos o exposto em Oliveira (2010, p. 98), para quem a "política pública é condição exclusiva do governo, no que se refere a toda a sua extensão (formulação, deliberação, implementação e monitoramento)". No entanto, ainda que seja materializada pelos governos, ela envolve diversos atores, não somente os "formais", por isso os “informais" também são importantes nesse processo (SOUZA, 2006, p. 36). Importa esclarecer que compreendemos como atores formais aqueles diretamente envolvidos com a materialização das políticas como, por exemplo, o governo, e os informais seriam, a nosso ver, aqueles que têm participação nas decisões de forma indireta como, por exemplo, a sociedade.

A política educacional ${ }^{6}$, segundo Oliveira (2010), refere-se ao que o governo faz (ou deixa de fazer) em educação, bem como aos impactos de suas ações (ou omissões). Para o autor, o termo "educação" é um conceito amplo para falar de políticas educacionais, visto que ela é algo que vai além do ambiente escolar, pois também consiste em tudo aquilo que se aprende socialmente, fora do ambiente formal de aprendizagem como, por exemplo, no trabalho, na igreja, na escola, na família, na rua etc. Portanto, segundo o autor as políticas públicas educacionais, em geral, aplicam-se às questões escolares, isto é, elas dizem respeito à educação escolar. Para o pesquisador,

\begin{abstract}
Nesse sistema, é imprescindível a existência de um ambiente próprio do fazer educacional, que é a escola, que funciona como uma comunidade, articulando partes distintas de um processo complexo: alunos, professores, servidores, pais, vizinhança e Estado (enquanto sociedade política que define o sistema através de políticas públicas). Portanto, políticas públicas educacionais dizem respeito às decisões do governo que têm incidência no ambiente escolar enquanto ambiente de ensinoaprendizagem. (OLIVEIRA, 2010, p. 96-97).
\end{abstract}

A partir das considerações apresentadas acerca das políticas educacionais, compreendemos que estas têm por intuito regular e orientar os sistemas de ensino e que

\footnotetext{
${ }^{6}$ Salientamos que a política educacional não é a única proveniente do termo política pública, visto que existem outras a ela relacionadas como, por exemplo, as políticas de saúde, políticas de transporte, políticas de segurança etc. Todavia, trazemos as definições do termo "política educacional" somente devido ao fato de este conceito ser próprio ao escopo deste artigo.
} 
irão influenciar na vida de todos os indivíduos, não apenas das crianças e adolescentes inseridas nas escolas, pois, conforme pontua Rajagopalan (2013), todos os cidadãos podem - e devem - participar expressando sua opinião, trazendo à tona as necessidades da comunidade.

Por fim, o último conceito apresentado é o termo políticas linguísticas visto que, em nossa concepção, quando falamos em políticas educacionais, inclui-se aí a aprendizagem de línguas.

Para Oliveira (2016), há duas perspectivas quando se refere ao termo política linguística: 1) as políticas linguísticas propriamente ditas, isto é, como parte das políticas públicas; e 2) da área acadêmica, inserida na subárea da linguística aplicada ou da sociolinguística, cuja história data de aproximadamente 60 anos "no meio universitário ocidental, e recém na adolescência no Brasil” (OLIVEIRA, 2016, p. 384). Nesse sentido, traremos, nesta seção, a perspectiva das políticas linguísticas como parte das políticas públicas "concebidas e executadas por instituições que têm ingerência na sociedade, como os Estados, os governos, as igrejas, as empresas, as ONGs e associações, e até as famílias" (OLIVEIRA, 2016, p. 382).

Uma política linguística pode ser ainda entendida como uma “intervenção informada, deliberada e sistemática concebida e acompanhada por especialistas da área da Linguagem (linguistas e linguistas aplicados) nas questões afeitas à convivência entre línguas e o status relativo delas no espaço nacional" (ALMEIDA FILHO, 2014, s.p.). No entanto, para Rajagopalan (2013), não são somente os especialistas da área que devem ter participação nas políticas (sejam elas linguísticas ou de outro caráter). Para o pesquisador, ainda que o linguista mereça ser consultado sobre as questões que envolvem as políticas linguísticas, todo e qualquer cidadão possui o direito e o dever de participar, de expressar suas opiniões, de ser ouvido e respeitado e de ser consultado, independentemente de sua área ou nível de escolaridade. Para Rajagopalan (2013, p. 22), com quem concordamos, o cidadão tem direito nas participações visto que "o que está em jogo [...] é o futuro de uma língua nacional ou outras questões de tamanha importância sobre as quais todos os cidadãos - sem exceção - têm ou, se não têm, devem ter direito igual e irrestrito de opinar".

Corroborando as ideias do autor, Oliveira (2016) destaca que, embora muitas vezes 
os linguistas tenham participação nas políticas linguísticas de forma a instruí-las ou legitimá-las, estes podem, também, não ter envolvimento direto com sua concepção e/ou execução, visto que uma parte significante das políticas linguísticas não é elaborada por linguistas nem mesmo com a participação destes.

A partir do exposto, entendemos que, ao falar da inserção de LEC, a opinião do cidadão comum (a comunidade escolar como professores, profissionais que atuam no contexto educacional, pais e alunos, por exemplo) deve ser considerada e tomada como legítima nesse processo que envolve uma decisão política.

Existe, ainda, a aproximação das políticas com as práticas locais "bem como às ideologias e motivações que levam os sujeitos a fazerem uma ou outra opção linguística" (SEVERO, 2013, p. 454). A respeito da opção linguística, isto é, a escolha de qual língua ofertar na escola, Shohamy (2006, p. 45) aponta que é por meio da política linguística "que as decisões são tomadas com relação às línguas preferidas que devam ser legitimadas, usadas, aprendidas e ensinadas em termos de onde, quando e em quais contextos"7. De acordo com Shohamy (2006, p. 77),

No atual ambiente político em que os estados estão se tornando mais multilíngues, multinacionais e, ao mesmo tempo, mais globais, os estudantes são solicitados a aprender línguas que refletem e afetam os interesses de diferentes grupos de maneiras bem diferentes. Esses idiomas preferidos podem incluir idiomas considerados importantes no mundo global, como é o caso do inglês na maioria dos países. Pode também incluir decisões para ensinar certas línguas como língua estrangeira/segunda no sistema educacional ${ }^{8}$.

O exposto pela autora ilustra, a nosso ver, exatamente a situação atual a qual se inserem as escolas públicas e privadas de EI e EFI no Brasil, posto que muitas passaram a incluir o ensino de uma LE já nos primeiros anos pelas demandas e pelos interesses da sociedade.

Compreendemos, deste modo, que os termos e seus respectivos conceitos se inter-

\footnotetext{
7 [...] that decisions are made with regard to the preferred languages that should be legitimized, used, learned and taught in terms of where, when and in which contexts (traduções foram feitas pelas autoras).

8 "In the current political environment where states are becoming more multilingual, multinational and at the same time more global, students are asked to learn language(s) that reflect and affect the interests of different groups in quite different ways. Such preferred languages may include languages that are considered important in the global world, as is the case with English in most countries. It may also include decisions to teach certain language(s) as a foreign/second language in the educational system".
} 
relacionam, uma vez que uma política pública, por exemplo, pode regulamentar uma política educacional e motivar uma reflexão e criação de uma política linguística.

Todavia, consideramos que as políticas estão ora direta e ora indiretamente relacionadas visto que, em nossa concepção, uma não depende da outra para existir, pois mesmo que tenhamos uma política linguística instaurada, esta não precisa estar, necessariamente, relacionada à política educacional ${ }^{9}$. Ou, ainda, a política linguística pode ter surgido por uma demanda da sociedade e somente depois de ser instaurada como uma política educacional ou uma política pública.

\section{O STATUS DA LÍNGUA INGLESA NO MUNDO, DOCUMENTO OFICIAIS E AS POLÍTICAS LINGUÍSTICAS PARA O ENSINO DE LÍNGUA INGLESA NOS ANOS INICIAIS DE ESCOLARIZAÇÃO NO BRASIL}

Segundo Crystal (2005), desde o século XVIII já havia a possibilidade de que a LI pudesse desempenhar um papel global. Todavia, foi somente na década de 90 que essa questão emergiu com mais intensidade por meio de pesquisas, livros e conferências os quais tentavam explicar como uma língua pode se tornar global, quais consequências pode causar e, além disso, por que a primeira língua candidata foi o inglês.

Para que uma língua ganhe este status, é necessário que ela seja usada por vários países no mundo e que, mesmo que haja poucos ou nenhum falante nativo, ela deve ter um lugar especial dentro de suas comunidades. Tal fenômeno pode ocorrer de duas formas: 1) a língua pode se tornar oficial ou semioficial e ser utilizada como meio de comunicação em áreas como governo, mídia, tribunais de justiça e sistema educacional, como é o caso do inglês, já que este possui algum tipo de status administrativo em mais de 70 países; e 2) uma língua pode se tornar prioridade no ensino de LE em um país, justificada pelo fato de mais de cem países terem o inglês como LE sendo que, na maioria deles, essa língua é reconhecida como a principal LE a ser ensinada nas escolas (CRYSTAL, 2005).

Para Crystal (2005, p. 22), "nenhuma outra língua [além da língua inglesa] é usada em tão larga escala - seja numericamente ou com semelhante alcance geográfico", impulsionada pela necessidade de uma língua comum (ou língua franca). Dessa forma,

\footnotetext{
${ }^{9}$ A exemplo dessa afirmação, elencamos sites que trazem seu conteúdo traduzido em vários idiomas que, a nosso ver, são exemplos de política linguística pelo fato de favorecer alguns idiomas e não outros; no entanto, não possui relação com a política educacional.
} 
com o advento da globalização, a LI passou a despertar maior interesse político, econômico, cultural e social visto ser ela o veículo de propagação de grande parte do conhecimento mundial, principalmente no que tange à ciência e à tecnologia. Todavia, especificamente para o ensino de LIC (como LE), embora seja uma tendência mundial (ROCHA, 2007; GIMENEZ, 2013), vem sendo desenvolvido sem muito planejamento (GIMENEZ, 2013; CHAGURI; TONELLI, 2013). Um dos motivos para isso, em nossa concepção, é a carência de documentos que ofereçam encaminhamentos legais e metodológicos para a condução desse ensino. Documentos subjacentes ao ensino de LE trazem considerações acerca da importância de sua aprendizagem no que se refere aos estudos somente a partir da segunda etapa do ensino fundamental, isto é, do sexto ano até chegar no ensino médio.

A esse respeito trazemos o exposto pela Base Nacional Comum Curricular (BNCC) (BRASIL, 2017, p. 239), documento mais recente o qual preconiza o ensino da LI sob a justificativa de que ao aprender a língua, esta "propicia a criação de novas formas de engajamento e participação dos alunos em um mundo social cada vez mais globalizado e plural”, podendo possibilitar aos aprendizes "acesso aos saberes linguísticos necessários para engajamento e participação, contribuindo para o agenciamento crítico dos estudantes e para o exercício da cidadania ativa”.

Todavia, importa dizer que as considerações contidas na BNCC dizem respeito ao ensino de LE somente a partir da segunda etapa do ensino fundamental, pois, no Brasil, de acordo com a resolução CNE/CEB 7/2010, que fixa as Diretrizes Curriculares Nacionais (DCNs) para o ensino de nove anos (BRASIL, 2010), a obrigatoriedade da oferta de uma LE acontece somente a partir do sexto ano e é facultativa nas etapas anteriores de escolaridade, isto é, na educação infantil (EI) e no EFI.

Do nosso ponto de vista, no entanto, a oferta de uma LE desde a infância amplia as possibilidades da criança construir suas próprias percepções de como sua língua funciona, no nosso caso, a língua portuguesa, e como diferentes modos de se expressar propiciam o agir no mundo por meio da língua que é "constitutivamente social" (RAJAGOPALAN, 2010, p. 11). Ademais, a aprendizagem de uma outra língua pode oportunizar a formação de indivíduos mais conscientes sobre modos de ser, pensar e agir por meio da língua(gem) e da valorização do outro. 
Além destes argumentos, alinhamo-nos ao discutido por Tonelli e Chaguri (2014), assim como em Rocha (2007), para quem o ensino de uma LEC, em especial no contexto público de escolarização, é uma questão de inclusão social. Para os autores, o ensino de uma LE desde a tenra idade

[...] pode contribuir para que o pequeno aprendiz faça conexões e crie hipóteses sobre as diferenças e as semelhanças entre as línguas, tendo consciência de que pode utilizá-la para estabelecer comunicação, transmitir ideias e compreender o mundo à sua volta. É essa interação com o mundo que pode promover a inclusão social das crianças. (TONELLI; CHAGURI, 2014, p. 265).

Na esteira de tal exposição, advogamos pela inserção compulsória de ao menos uma LE já na EI. Gimenez (2013) chama atenção para as DCNs (BRASIL, 2010) as quais preveem a possibilidade de oferta de LE para esse público ao preconizar que "nas escolas que optarem por incluir Língua Estrangeira nos anos iniciais do Ensino Fundamental, o professor deverá ter licenciatura específica no componente curricular" (BRASIL, 2010, p. 9) e que este é um dos poucos textos que aborda essa questão.

Avila e Tonelli (2018), ao discutirem a temática, consideram o projeto de lei $\mathrm{n}^{\circ}$ $1.302 / 2015$ o qual propõe alteração do $\S 5^{\circ}$ do art. 26 da LDB (BRASIL, 2007) de forma a tornar o ensino da LE obrigatório a partir do primeiro ano do ensino fundamental. De acordo com o referido projeto de lei,

Na parte diversificada do currículo será incluído, obrigatoriamente, a partir do primeiro ano do ensino fundamental, o ensino de pelo menos uma língua estrangeira moderna, cuja escolha ficará a cargo da comunidade escolar, dentro das possibilidades da instituição. (CÂMARA DOS DEPUTADOS, 2015, p. 2) (grifo nosso).

Desse modo, compreendemos que as DCNs consistem em uma política pública que rege a educação brasileira e que, portanto, pode ser tomada como ponto de partida para a criação de uma política linguística que contemple, de forma compulsória, a inserção de LE nos currículos dos anos iniciais, conforme propõe o projeto de lei $\mathrm{n}^{\circ} 1.302 / 2015$, de modo a assegurar ao aluno já na EI a igualdade de oportunidades no que tange à aprendizagem de uma LE (CHAGURI; TONELLI, 2013). É preciso dizer ainda que, a nosso ver, a 
criação de documentos norteadores para o ensino de LEC poderá servir de subsídio tanto para os professores em relação aos conteúdos e às metodologias a serem adotados, tanto aos gestores para a implantação e manutenção da oferta da língua.

Além das políticas linguísticas servirem de suporte para os professores, elas também poderão subsidiar os demais envolvidos no contexto escolar. No entanto, é preciso lembrar que, para que essas ações sejam efetivadas, as decisões sobre políticas educacionais não podem ser deixadas apenas nas mãos dos políticos, embora saibamos que são eles, em última instância, os responsáveis legais pela fixação das políticas (CHAGURI; TONELLI, 2013).

A elaboração de uma política pública educacional que traga orientações aos gestores sobre a implementação da LE no currículo das escolas de EI e EFI, bem como aos professores de modo a subsidiar seu trabalho, é, em nossa concepção, imprescindível, porque a falta de regulamentação dificulta a implantação da LI no ensino público (MELLO, 2013; GINI, 2017).

É neste sentido que defendemos a importância de documentos que orientem e formalizem o trabalho do professor quanto aos conteúdos e aos modos de ensinar LE para essa faixa etária, visto que os docentes, em sua maioria, não possuem formação para atuar nesse nível de ensino (SANTOS, 2005; TUTIDA, 2016; TONELLI; FERREIRA; BELOCORDEIRO, 2017).

\section{PESQUISAS BRASILEIRAS SOBRE INICIATIVAS LOCAIS DE INSERÇÃO DE LIC: UM BREVE PANORAMA}

Apresentamos, nesta seção, sete pesquisas identificadas a partir de cartografia (KASTRUP, 2007) realizadas pelo Grupo de Pesquisa FELICE (CAPES/CNPq) e publicadas por Tonelli e Pádua (2017) as quais constituem o corpus analisado para atingir o objetivo a que nos propusemos.

A pesquisa de Mello (2013), intitulada Ensino de Inglês nos anos iniciais do ensino fundamental: um estudo de política pública no município de Rolândia - PR, tratou da implementação da LI no EFI na cidade de Rolândia no ano de 2010 por meio da Lei ${ }^{\circ}$ 3.446/2010. O objetivo de sua dissertação foi investigar os motivos que levaram à obrigatoriedade da oferta da LI na cidade, bem como compreender as justificativas que 
embasaram tal ação. Nesse sentido, a autora reflete acerca das ideologias que permeiam os documentos e os discursos daqueles que a articularam e a legitimaram. A autora analisa os documentos que sustentam a lei, tais como um parecer produzido a fim de defender a lei na Câmara Municipal de vereadores; entrevistas com os envolvidos em sua criação, redação e defesa; e textos produzidos pela mídia local. Como resultados, ela identificou as relações entre LI e globalização, bem como semelhanças entre os contextos local e global no que concerne às dificuldades e desafios na implementação do ensino.

A dissertação de Vicentin (2013) faz uma reflexão acerca das políticas linguísticas de ensino de LI para os anos iniciais do EFI público, considerando representações presentes em discursos para professores de inglês que atuam na cidade de Campinas, São Paulo e o documento Diretrizes Curriculares de Língua Inglesa dos Anos Iniciais, por eles sistematizado e elaborado. Os dados foram gerados a partir de entrevistas semiestruturadas individuais com os professores participantes da investigação e em notas de diários de campo de encontros de formação continuada da Secretaria Municipal de Educação de Campinas. Os resultados da pesquisa indicaram, entre outras questões, que, embora os professores de LI entrevistados tenham atuado como policy makers de um modelo de política linguística ascendente, eles não se reconhecem, ou parecem ainda não ter consciência do seu papel no estabelecimento dessas políticas. Além disso, as representações encontradas nos discursos são condizentes, em alguns momentos, com os pressupostos e as orientações do documento que sistematizaram e elaboraram, mas, em outros, se contrapõem. A autora concluiu ainda que, para que seja possível a implementação efetiva do ensino de LIC na matriz curricular oficial dos anos iniciais, é necessário haver um modelo de política linguística específico para LEC.

A pesquisa empreendida por Barbosa (2014) trata especificamente de práticas avaliativas em inglês no contexto de LEC, no primeiro ano do ensino fundamental das escolas públicas no município de Castanhal - PA, e, por isto, a consideramos relevante no escopo da presente discussão, justamente pelo fato de que a avaliação é uma etapa imprescindível no processo de ensino e aprendizagem e, inevitavelmente, está atrelada ao campo investigativo aqui proposto. A pesquisadora estudou quais as orientações contidas nos documentos oficiais municipais no que diz respeito ao ensino e à avaliação em LEC, descreveu as práticas avaliativas desenvolvidas pelos docentes naquele contexto, 
averiguou a integração das práticas com os objetivos de ensino e aprendizagem de LEC e indicou pistas que possam, teórica e metodologicamente, tornar essas práticas mais eficazes. Os resultados da análise indicam a ausência de coerência entre as práticas avaliativas e os objetivos e princípios do ensino de LEC. Os dados revelam ainda a falta de formação para ensinar, avaliar e elaborar programas de LEC, aliada a uma já conhecida tendência em se priorizar aspectos estruturais no ensino de línguas estrangeiras, em detrimento de atividades comunicativas.

Barbosa (2014) adverte a necessidade de promover outras pesquisas que investiguem as práticas avaliativas em LEC e, da urgência em se definir diretrizes oficiais nacionais para o ensino e avaliação que levem em consideração as características e necessidades das crianças nos contextos específicos.

$\mathrm{Na}$ dissertação de Seccato (2016), intitulada Políticas Linguísticas e as Representações da Prática Docente no Ensino Fundamental I: Língua Inglesa em Foco, a autora analisa o Projeto Londrina Global (PLG), o qual é destinado ao ensino de LI no EFI das escolas da cidade de Londrina-PR, implementado no ano de 2008 e pontua o Guia Curricular de Ensino de Língua Inglesa (GCLI), documento elaborado para orientar a prática das professoras que atuam no PLG. Os dados foram colhidos do GCLI e do questionário aplicado às professoras de forma a destacar as representações das docentes quanto ao guia e à relação entre local e global. Como resultados, a pesquisadora aponta que os princípios que norteiam o GCLI foram exemplificados nos relatos das professoras os quais forneceram indícios para reflexões quanto às possíveis conexões entre políticas linguísticas e a prática docente.

Tanaca (2017), em sua tese intitulada Aprendizagem expansiva em espaços híbridos de formação continuada de professoras de inglês para crianças no Projeto Londrina Global (PLG), analisa a implementação da LI na cidade de Londrina no que diz respeito à formação continuada das participantes do PLG. A autora examinou a transcrição de gravações de encontros de formação continuada com professoras e coordenadoras/formadoras do PLG bem como do projeto $^{10}$ intitulado Desenvolvimento de Atividades de Ensino de Inglês para Crianças. De acordo com a autora, os resultados

\footnotetext{
${ }^{10}$ Projeto de pesquisa e extensão através da produção coletiva de material didático em inglês do Departamento de Letras Estrangeiras Modernas/Núcleo de Apoio Pedagógico da Universidade Estadual de Londrina, então coordenado pela Profa. Dra. Denise Ismênia Bossa Grassano Ortenzi.
} 
mostraram que práticas híbridas de formação continuada "constituem espaços desestabilizadores de saberes que potencializam novos modos de ser e saber da formação e da aprendizagem docente para o ensino de LIC" (TANACA, 2017, p. 8).

A dissertação de Gini (2017) trata da implementação do ensino de LIC no EFI nas cidades de Ibiporã, no ano de 2010, Maringá, em 2014 e também Londrina, em 2008, de forma a identificar quais elementos constituem a atividade educacional que permeiam essa iniciativa objetivando identificar os elementos constitutivos da atividade educacional no ensino de LIC. Foram realizadas entrevistas com responsáveis pela implementação de LIC nessas cidades. A partir dos resultados identificados, a autora elaborou uma "Carta ao Gestor" para auxiliar gestores em momentos de implementação de LIC em seus municípios, contemplando os elementos da atividade educacional identificados nas análises.

Avila (2019), por sua vez, em sua dissertação intitulada Ensino de Inglês nos anos iniciais e internacionalização do ensino superior: um estudo de caso em um município do Paraná, investigou as motivações para a inserção da língua inglesa em uma escola municipal pública de EFI situada em uma cidade de aproximadamente 3.000 habitantes ao norte do Estado do Paraná. A autora objetivou estabelecer possíveis contribuições do ensino de inglês nos anos iniciais para a internacionalização do ensino superior. Avila (2019) realizou entrevistas com as principais atrizes envolvidas, direta ou indiretamente, no processo de implementação e manutenção da LI no currículo da escola investigada (secretárias de educação, diretoras e professoras). Os resultados mostraram motivações de diferentes naturezas para a inserção da LI na escola e, embora as participantes não tenham utilizado nas entrevistas o termo "internacionalização", esta relação pôde ser estabelecida pela autora ao mencionar as possíveis vantagens desse ensino desde esta etapa de escolarização para os alunos quando/se, futuramente, ingressarem no ensino superior.

Tendo apresentado o aporte teórico que sustenta esta discussão, na seção subsequente apresentamos os dados analisados e, na sequência, traçamos algumas possíveis reflexões sobre iniciativas locais de implantação de LEC e o que isto pode representar em termos de políticas linguísticas em nosso país. 


\section{REVISTA $\mathbf{X}$}

\section{ANÁLISE DOS DADOS}

Para que possamos atingir o objetivo traçado - apresentar uma reflexão sobre a implementação de aulas de LEC na rede pública de ensino em nosso país e o que tais ações podem indicar em termos de políticas linguísticas - para fins de análise dos dados, extraímos dos resumos ${ }^{11}$ das teses e dissertações analisadas, marcas linguísticas que nos permitam identificar como tais políticas estão sendo estabelecidas nos contextos aqui considerados.

Quadro 1: Marcas linguísticas da presença de políticas linguísticas no ensino de LIC nas pesquisas analisadas.

\begin{tabular}{|c|c|c|}
\hline AUTORA & ESCOPO CENTRAL & TRAÇOS LINGUÍSTICOS \\
\hline Mello (2013) & $\begin{array}{l}\text { Tratou da implementação da LI no EFI na } \\
\text { cidade de Rolândia no ano de } 2010 \text { por } \\
\text { meio da lei } n^{\circ} 3.446 / 2010 \text {. }\end{array}$ & $\begin{array}{l}\text { Implementação; } \\
\text { Língua inglesa; } \\
\text { Lei. }\end{array}$ \\
\hline Vicentin (2013) & $\begin{array}{l}\text { Os professores de LI entrevistados têm } \\
\text { atuado como policy makers de um modelo } \\
\text { de política linguística ascendente, eles } \\
\text { não se reconhecem, ou parecem ainda não } \\
\text { ter consciência do seu papel no } \\
\text { estabelecimento dessas políticas. } \\
\text { A autora concluiu ainda que, para que seja } \\
\text { possível a implementação efetiva do } \\
\text { ensino de LIC na matriz curricular oficial } \\
\text { dos anos iniciais, é necessário haver um } \\
\text { modelo de política linguística específico } \\
\text { para LEC. }\end{array}$ & $\begin{array}{l}\text { Policy makers de um modelo de política } \\
\text { linguística ascendente; } \\
\text { Papel no estabelecimento dessas políticas; } \\
\text { Implementação efetiva; } \\
\text { Modelo de política linguística específico para } \\
\text { LEC. }\end{array}$ \\
\hline Barbosa (2014) & $\begin{array}{l}\text { Analisou quais as orientações contidas nos } \\
\text { documentos oficiais municipais no que } \\
\text { diz respeito ao ensino e à avaliação em } \\
\text { LEC, descreveu as práticas avaliativas } \\
\text { desenvolvidas pelos docentes naquele } \\
\text { contexto, analisou a integração das práticas } \\
\text { com os objetivos de ensino e aprendizagem } \\
\text { de LEC e indicou pistas que possam, } \\
\text { teórica e metodologicamente, tornar essas } \\
\text { práticas mais eficazes. } \\
\text { Os dados revelam [...]a falta de formação } \\
\text { para ensinar, avaliar e elaborar }\end{array}$ & $\begin{array}{l}\text { Orientações; } \\
\text { Documentos oficiais municipais; } \\
\text { Falta de formação para ensinar, avaliar e } \\
\text { elaborar programas de LEC. }\end{array}$ \\
\hline
\end{tabular}

${ }^{11}$ Justificamos tal opção porque o resumo em gêneros acadêmicos apresenta a síntese da pesquisa. 


\section{REVISTA $\mathbf{X}$}

\begin{tabular}{|c|c|c|}
\hline & programas de LEC. & \\
\hline Seccato (2016) & $\begin{array}{l}\text { Como resultados, aponta que os princípios } \\
\text { que norteiam o Guia Curricular Língua } \\
\text { Inglesa - documento elaborado para } \\
\text { orientar a prática das professoras que atuam } \\
\text { no Projeto Londrina Global. } \\
\text { [...] da cidade de Londrina foram } \\
\text { exemplificados nos relatos das professoras } \\
\text { os quais forneceram indícios para reflexões } \\
\text { quanto às possíveis conexões entre } \\
\text { políticas linguísticas e a prática docente. }\end{array}$ & $\begin{array}{l}\text { Língua Inglesa; } \\
\text { Projeto; } \\
\text { Políticas linguísticas e a prática docente. }\end{array}$ \\
\hline Tanaca (2017) & $\begin{array}{l}\text { Práticas híbridas de formação continuada } \\
\text { constituem espaços desestabilizadores de } \\
\text { saberes que potencializam novos modos de } \\
\text { ser e saber da formação e da } \\
\text { aprendizagem docente para o ensino de } \\
\text { LIC. }\end{array}$ & $\begin{array}{l}\text { Formação continuada; } \\
\text { Formação e aprendizagem docente; } \\
\text { Ensino de LIC. }\end{array}$ \\
\hline Gini (2017) & $\begin{array}{l}\text { A partir dos resultados identificados, a } \\
\text { autora elaborou uma Carta ao Gestor para } \\
\text { auxiliar gestores em momentos de } \\
\text { implementação de LIC em seus } \\
\text { municípios, contemplando os elementos da } \\
\text { atividade educacional identificados nas } \\
\text { análises. }\end{array}$ & Implementação de LIC. \\
\hline Avila (2019) & $\begin{array}{l}\text { Investigou as motivações para a inserção } \\
\text { da LI em uma escola municipal pública } \\
\text { de EFI situada em uma cidade de } \\
\text { aproximadamente } 3.000 \text { habitantes ao norte } \\
\text { do Estado do Paraná e objetivou estabelecer } \\
\text { possíveis contribuições do ensino de inglês } \\
\text { nos anos iniciais para a internacionalização } \\
\text { do Ensino Superior. }\end{array}$ & $\begin{array}{l}\text { Inserção da LI em uma escola municipal } \\
\text { pública de EFI; }\end{array}$ \\
\hline
\end{tabular}

Fonte: as autoras.

Conforme Mello (2013), a cidade de Rolândia foi colonizada por alemães, portanto, ao surgir a oportunidade de inserção de uma LE no EFI, o alemão poderia ter sido a língua escolhida, visto que traria uma identificação cultural da comunidade local. No entanto, ao implementar já no formato de lei a LI, fica evidente o papel desta língua na construção de uma política linguística, de fato. Nota-se, então, que, por meio de lei, ou seja, contexto de produção de textos, fica estabelecida a LI muito provavelmente por causa 
da influência da globalização (SHOHAMY, 2006) e, ao contrário do que poderia ser, não foi a língua alemã inserida nas escolas, o que traria identificação com a cultura local.

Semelhantemente, dois dos três locais investigados por Gini (2017), a saber Maringá, Ibiporã e Londrina, inseriram a LI, e não outra LE, por força de lei e, um contexto oferta a língua por meio de projeto. Deste modo, é preciso reconhecer, novamente, a força da LI enquanto língua da globalização (SHOHAMY, 2006) bem como o fato de que os textos que orientam o ensino de LIC foram produzidos localmente a partir de uma demanda (BOWE et al.,1992; Ball, 1994). A autora considera que a ausência de políticas linguísticas para o ensino de LEC faz com que a implantação e a regulamentação do ensino de LIC fique "a cargo das instituições de ensino" (GINI, 2017, p.146).

$\mathrm{Na}$ esteira desta exposição, recuperamos Vicentin (2013) que conclui sua dissertação afirmando que os professores de LI para ela, são policy makers de um modelo de política linguística ascendente, mas no contexto investigado não são conscientes do papel no estabelecimento dessas políticas. Ao finalizar dizendo que a implementação efetiva requer um modelo de política linguística específico para LEC indica a ideia da importância de uma política de texto, pois esta pode orientar melhor o ensino e a formação do profissional que atuará no referido contexto.

Retomando Ball (1994), a política é um conjunto de práticas realizadas em ambientes locais; é texto, mas é também uma ação a qual é representada de maneiras diferentes por diferentes atores e interesses. Nos destaques apresentados no Quadro 1 a partir das constatações das pesquisadoras, fica evidente que no contexto de Mello (2013), por exemplo, a política linguística existe por força de lei, mas não se considerou a cultura local. Naquele espaço, a LI, enquanto língua globalizante, tomou força e assumiu o texto nas práticas educacionais.

Já no caso de Vicentin (2013), a política linguística existe em sua prática local contexto de prática - e foi construída pelos próprios professores de LI (SECCHI, 2013) os quais parecem esperar um texto "de fora" - política ascendente - para legitimar suas ações. Neste cenário, as ideias de Oliveira (2010) fazem sentido posto que, para ele, a política é também praticada pela sociedade civil.

O mesmo é apontado por Barbosa (2014) que, ao analisar as orientações contidas 
nos documentos oficiais municipais do seu contexto de atuação no que diz respeito ao ensino e à avaliação em LEC, concluiu a falta de formação para ensinar, avaliar e elaborar programas de LEC. O que sugere que a ausência de um documento orientador para o ensino impacta na formação de professores, pois se a oferta não é obrigatória, não há a necessidade de formação, em especial, a inicial.

Tanaca (2017) e Seccato (2016) que, sob vieses diferentes, investigaram os mesmos contextos, reforçam as ações geradas frente a oferta de LIC por meio de projeto, o que fortalece nosso entendimento de que a política existe na prática. Todavia, o que nos falta é a política no texto para que esta promova a formação (inicial e continuada) de professores.

A partir dos termos destacados no Quadro 1, evidenciamos que, mesmo frente ao silenciamento de documentos educacionais (na BNCC, em especial) em relação à regulamentação da oferta de LE, os próprios municípios constituíram suas leis para que tal processo se concretizasse na prática por uma comunidade que se pauta no fazer diário, construindo-as e legitimando-as localmente. Importa ressaltar que, embora acreditemos na importância do ensino e da valorização de outras LE, os textos analisados recuperam uma discussão bastante presente sobre o fato de que quando falamos de seu ensino, incluindo na infância, a LI é a única língua tematizada. Compreendemos, assim como Magiolo e Tonelli (no prelo), ser preciso ter em conta que, embora seja esta a língua da globalização - conforme discutimos anteriormente - e, portanto, os documentos balizadores da educação brasileira a coloquem como a única cuja oferta é obrigatória, pouco tem sido discutido sobre a importância de promover, em especial nas crianças, a conscientização e a abertura à outras línguas (TONELLI; CORDEIRO, 2014).

\section{CONSIDERAÇÕES FINAIS}

Neste artigo apresentamos uma breve reflexão sobre a implementação de aulas de LE nos anos iniciais, em especial, na rede pública de ensino em nosso país e o que tais ações podem indicar sobre políticas linguísticas. Para isto, analisamos os resumos de teses e dissertações as quais tratam, direta ou indiretamente, dos desdobramentos inerentes a iniciativas locais para a oferta da LI na infância em contextos públicos e os possíveis reflexos nas políticas. 
Conforme demonstramos, ainda que oficialmente não tenhamos uma política (texto) que oriente a implementação e o ensino de LEC, nos municípios onde esta oferta acontece, podemos identificar que existem políticas linguísticas na prática. Reiteramos a importância de documentos que orientem tal ensino visto que estes, talvez, possam exigir, por meio de lei, a inserção de LE no EFI bem como sua continuidade, pois, sem diretrizes, a oferta fica a cargo da administração municipal vigente que, em sua maioria, não dispende verbas ou mesmo não possui conhecimento suficiente de como funciona esse ensino.

Não queremos com isso dizer que a política (texto/palavras) será a "solução" para o problema. Entendemos, a partir dos pressupostos teóricos que fundamentam esta pesquisa e das análises empreendidas, que as políticas (ação) existem e têm sido criadas (em respostas a problemas que surgem da prática) por profissionais da educação que influenciam seus processos de criação e de execução, conforme Bowe et al. (1992).

Portanto, reafirmamos que o que falta é uma política pública nacional que insira LEC de forma compulsória para que, assim, tal ensino seja visto como parte do sistema educacional brasileiro e passe a haver, por parte do Estado, a responsabilidade em investimentos financeiro e humano. Ponderamos também as implicações na ausência de formação de professores para atuar nesse nível de escolaridade visto que, como abordado, sem a regularização da oferta perpetua-se a inexistência de espaços formativos nos cursos de graduação e pós-graduação.

Por fim, questionamos se seriam todos estes pontos aqui levantados propositalmente silenciados, posto que, a própria BNCC, contraditoriamente apregoa, em seu texto, diversidade, equidade e igualdade, ao se esquivar da responsabilidade pela regulamentação da oferta de LEC, desobriga os órgãos de governo a dar condições para que este ensino aconteça. Seria este um silenciamento ou uma omissão proposital?

\section{AGRADECIMENTOS}

Agradecemos aos membros do Grupo de Pesquisa FELICE (CNPq), pelo empenho na manutenção do mapeamento de teses e dissertações no campo investigado e pela constante partilha, não só das pesquisas, mas da vida. 


\section{REFERÊNCIAS}

ALMEIDA FILHO, J. C. P. Receber ou Implantar Políticas de Ensino de Línguas. SIPLE, 8 ed., ano 5, n. 1, 2014.

AVILA, P. A.; TONELLI, J. R. A. A ausência de políticas para o ensino de língua estrangeira no ensino fundamental I: reflexões acerca da obrigatoriedade da oferta nos currículos das escolas municipais públicas. Revista X, Curitiba, v. 13, n. 2, p. 111-122, 2018. Disponível em: <https://revistas.ufpr.br/revistax/article/view/55588>. Acesso em: 27 jul. 2020.

AVILA, P. A. Ensino de inglês nos anos iniciais e internacionalização do ensino superior: um estudo de caso em um município do Paraná. 2019. 233 f. Dissertação (Mestrado em Estudos da Linguagem) - Universidade Estadual de Londrina, Londrina, 2019.

BALL, S. J. Education reform: a critical and post-structural approach. Buckingham: Open University Press, 1994.

BALL, S. J.; MAINARDES, J. (Orgs.) Políticas educacionais: questões e dilemas. São Paulo: Cortez, 2011.

BARBOSA, E. G. Avaliação da aprendizagem em língua inglesa no primeiro ano do ensino fundamental em escolas públicas do município de Castanhal (PA). 2014. $170 \mathrm{f}$. Dissertação (Mestrado em Letras) - Universidade Federal do Pará, Instituto de Letras e Comunicação, Belém, 2014.

BOWE, R.; BALL, S.; GOLD, A. Reforming education \& changing schools: case studies in policy sociology. London: Routledge, 1992.

BRASIL. Lei Federal n. 8069, de 13 de julho de 1990. ECA Estatuto da Criança e do Adolescente.

Disponível

em: $<$ http://www.crianca.mppr.mp.br/arquivos/File/publi/camara/estatuto_crianca_adolescente 9ed.pdf>. Acesso em: 27 jul. 2020.

BRASIL. Lei $n^{\circ}$ 9.394, de 20 de dezembro de 1996. Lei de Diretrizes e Bases da Educação Nacional. Brasília, DF. 2007.

BRASIL. Ministério da Educação. Base Nacional Comum Curricular. Brasília, DF, 2017. Disponível em: < http://basenacionalcomum.mec.gov.br> Acesso em: 09 set. 2020.

BRASIL. Ministério da Educação. Conselho Nacional de Educação. Câmara Superior de Educação. Resolução $n^{o}$ 7, de 14 de dezembro de 2010. Fixa Diretrizes Curriculares Nacionais para o Ensino Fundamental de 9 (nove) anos. Brasília, DF, 2010. Disponível em: <http://portal.mec.gov.br/dmdocuments/rceb007_10.pdf> Acesso em: 27 abr. 2020. 
CÂMARA DOS DEPUTADOS. Projeto de Lei $n^{\circ} 1.302$, de 2015. Altera o $\S 5^{\circ}$ do art. 26 da Lei $\mathrm{n}^{\circ}$ 9.394, de 20 de dezembro de 1996, que estabelece as diretrizes e bases da educação nacional, para instituir a obrigatoriedade do ensino de língua estrangeira moderna a partir do primeiro ano do ensino fundamental. Disponível em: $<$ https://www.camara.leg.br/proposicoesWeb/prop_mostrarintegra?codteor=1335778 $>$. Acesso em: 09 set. 2020.

CHAGURI, J. P.; TONELLI, J. R. A. Existe uma política de Ensino-Aprendizagem de Língua Estrangeira para crianças? In: TONELLI, J. R. A.; CHAGURI, J. P. (Orgs.) Ensino de Lingua Estrangeira para Crianças: O Ensino e a Formação em Foco. 2 ed. Curitiba: APPRIS, 2013, p. 37-58.

CORREA, L. N. Políticas Educacionais e educação inclusiva com foco no ensino de Línguas Estrangeiras para Surdos. 2013. 128 f. Dissertação (Mestrado em Estudos da Linguagem) - Universidade Estadual de Londrina, Londrina, 2013.

CRYSTAL, D. A revolução da linguagem. Tradução de Ricardo Quintana. Rio de Janeiro: Zahar, 2005.

ESTADO. In: Dicionário Online Michaelis. Disponível em: $<$ https://michaelis.uol.com.br/moderno-portugues/busca/portugues-brasileiro/estado/>. Acesso em: 19 abr. 2020.

GIMENEZ, T. A ausência de políticas para o ensino da língua inglesa nos anos iniciais de escolarização no Brasil. In: NICOLAIDES, C.; SILVA, K. A. da; TILIO, R.; ROCHA, H. C. (Orgs.). Política e Políticas Linguísticas. Campinas, SP: Pontes/ALAB, p. 19-42, 2013.

GINI, K. M. P. Elementos constitutivos na implementação de língua inglesa nos anos iniciais do ensino fundamental em três municípios do norte do Paraná. 2017. $186 \mathrm{f}$. Dissertação (Mestrado em Estudos da Linguagem) - Universidade Estadual de Londrina, Londrina, 2017.

KASTRUP, V. O funcionamento da atenção no trabalho do cartógrafo. Psicologia e Sociedade, v. 19, n. 1, jan./ abr. Porto Alegre, 2007. Disponível em: $<$ https://www.scielo.br/scielo.php?pid=S010271822007000100003\&script=sci_abstract\&t $\underline{\operatorname{lng}=\mathrm{pt}}>$. Acesso em: 27 jul. 2020.

MAGIOLO, G. M; TONELLI, J. R. A (no prelo). Que inglês é esse que ensinamos na escola? Reflexões para elaboração de proposta didática para educação linguística na infância.

MAINARDES, J. Abordagem do ciclo de políticas: uma contribuição para a análise de política educacional. Revista Educação Social. v. 27, n. 94, p. 47-69, abr. 2006. Disponível em: <https://www.scielo.br/pdf/es/v27n94/a03v27n94.pdf $>$. Acesso em: 27 jul. 2020. 
MELLO, M. G. B. Ensino de inglês nos anos iniciais do ensino fundamental: um estudo de política pública no município de Rolândia, PR. 2013. 149 f. Dissertação (Mestrado em Estudos da Linguagem) - Universidade Estadual de Londrina, Londrina, 2013.

OLIVEIRA, A. F. Políticas Públicas Educacionais: conceito e contextualização numa perspectiva didática. In: OLIVEIRA, A. F.; PIZZIO, A.; FRANÇA, G. (Orgs.). Fronteiras da Educação: desigualdades, tecnologias e políticas. Goiás: Editora PUC, p. 92-99, 2010.

OLIVEIRA, G. M. Políticas Linguísticas: uma entrevista com Gilvan Müller de Oliveira. ReVEL, v.14, n.26, p.382-389, 2016. Disponível em: $<$ http://www.revel.inf.br/files/e92f933a3b0ca404b70a1698852e4ebd.pdf $>$. Acesso em: 27 jul. 2020.

RAJAGOPALAN, K. Política linguística: do que é que se trata, afinal? In: NICOLAIDES, C.; SILVA, K. A. da; TILIO, R.; ROCHA, H. C. (Orgs.). Política e Políticas Linguísticas.1. ed. Campinas, SP: Pontes/ALAB, v. 1, 2013, p. 19-42.

RAJAGOPALAN, K. A língua estrangeira para crianças: um tema no mínimo ambíguo. In: ROCHA, C. H.; TONELLI, J. R.A.; SILVA, K. A. (Orgs.). Língua estrangeira para crianças: ensino-aprendizagem e formação docente. 1. ed. Campinas, SP: Pontes, 2020, p.9-12.

ROCHA, C. H. O ensino de LE (inglês) para crianças do ensino fundamental público nas transdisciplinaridade da Lingüística Aplicada. In: TONELLI, J. R. A.; RAMOS, S. G. M. (Orgs.). O ensino de LE para crianças: reflexões e contribuições. Londrina: Moriá, p.134, 2007.

SANTOS, L. I. S. Crenças acerca da inclusão da língua inglesa nas séries iniciais: quanto antes melhor? 2005. 230 f. Dissertação (Mestrado em Estudos da Linguagem) Universidade Federal do Mato Grosso, 2005.

SECCATO, M. G. Políticas linguísticas e as representações da prática docente no ensino fundamental I: língua inglesa em foco. 2016. 176 f. Dissertação (Mestrado em Estudos da Linguagem) - Universidade Estadual de Londrina, 2016.

SECCHI, L. Políticas públicas: conceitos, esquemas de análise, casos práticos. 2.ed. São Paulo: CENGAGE Learning, 2013.

SEVERO, C. G. Política(s) linguística(s) e questões de poder. ALFA: Revista de Linguística, v. 57, n. 2, p. 451-473, 2013. Disponível em: $<$ https://www.scielo.br/pdf/alfa/v57n2/06.pdf>. Acesso em: 27 jul. 2020.

SHOHAMY, E. G. Language policy: hidden agendas and new approaches. Canadá: Routledge, 2006. 
SOUZA, C. Políticas públicas: uma revisão da literatura. Sociologias, Porto Alegre, v. 8, n. 16, p. 20-45, 2006. Disponível em: <https://www.scielo.br/pdf/soc/n16/a03n16>. Acesso em: 27 jul. 2020.

TANACA, J. J. C. Aprendizagem expansiva em espaços híbridos de formação continuada de professoras de Inglês para crianças no Projeto Londrina Global. 2017. 255 f. Tese (Doutorado em Estudos da Linguagem) - Universidade Estadual de Londrina, Londrina, 2017.

TONELLI, J. R. A.; PÁDUA, L. S. O estado da arte de pesquisas sobre ensino e formação de professores de línguas estrangeiras para crianças. In: TONELLI, J. R. A.; PADUA, L. S.; OLIVEIRA, T. R. (Orgs.) Ensino e formação de professores de línguas estrangeira para crianças no Brasil. Curitiba: APPRIS, p.17-40, 2017.

TONELLI, J. R. A.; FERREIRA, O. H. S.; BELO-CORDEIRO, A. E. Remendo novo em vestido velho: uma reflexão sobre os cursos de letras-inglês. REVELLI-Revista de Educação, Linguagem e Literatura, v. 9, n. 1, p. 124-141, mai., 2017. Disponível em: $<$ https://www.revista.ueg.br/index.php/revelli/article/view/5666 $>$. Acesso em: 27 jul. 2020 .

TONELLI, J. R. A.; CORDEIRO, G. S. Refletir sobre as línguas para aprendê-las: uma perspectiva de ensino-aprendizagem de inglês por meio de um gênero textual para (na) educação infantil. Revista MOARA, n.42, p.45-63, jul./dez., 2014. Disponível em $<$ https://periodicos.ufpa.br/index.php/moara/article/view/2055>. Acesso em 09 set. 2020.

TONELli, J. R. A.; CHAGURI, J. P. A importância de uma língua estrangeira na educação infantil. In. TONELLI, J. R. A.; CHAGURI, J. P. (Orgs.). Espaço para reflexão sobre ensino de línguas. Maringá: EDUEM, p. 247-275, 2014.

TUTIDA, A. F. Ensino de língua inglesa para crianças: questões sobre formação de professores e os saberes da prática. 2016. 339 f. Dissertação (Mestrado em Estudos da Linguagem) - Universidade Estadual de Londrina. Londrina, 2016.

VICENTIN, K. A. Inglês nos anos iniciais no Ensino Fundamental público: de representações de professores a políticas linguísticas. 2013. 149 f. Dissertação (Estudos da Linguagem) - Universidade Estadual de Campinas. Campinas, 2013.

Recebido em: 30 abr. 2020.

Aceito em: 05 out. 2020. 